\title{
Living with a mentally handicapped member of the family
}

\author{
D. J. BICKNELL \\ M.D., F.R.C.Psych.
}

\author{
St George's Hospital Medical School, Cranmer Terrace, London SWI7 ORE
}

\section{What is mental handicap?}

Mentally handicapped people share with very few other client groups the indignity of being defined in law, namely that they are unable to guard themselves against exploitation and unable to lead an independent existence. While some are considered capable of responding to special treatment and training, all have brain disorder, disease or damage which has manifested itself by reducing intellect during the developmental period, usually taken to be up to the age of 18 years. This essentially negative definition, based on little else but an expression of developmental delay resulting in intellectual and social incompetence encompasses a group of individuals, approximately three per thousand in the general population, who present to their families, care groups, educators and to society a set of challenges which in the past have been dealt with by the process of segregation into large institutions.

There has been a trend since 1959 to develop community care services according to local priorities which themselves have been based on the particular values and beliefs about mentally handicapped people, held by the planners of both health and social services. Consequently community care throughout the country has been uneven in its development, few evaluative studies have been done and support for families who wish to keep their mentally handicapped dependents at home varies from a totally absent or inappropriate service to a few shining examples of flexible, sensitive and skilful clientcentred and family-centred services which enable families to cope with no psychological, social or financial embarrassment.

Part of the development of community care has been a trend to value the care within the family home and by implication criticize those parents who choose an alternative pattern of care, in particular if this involves the large, long-stay mental handicap hospital. This trend, from the pressure and consumer groups in particular, has helped to force the pace of change but some families have suffered through lack of community care support and have borne criticism from the more reactionary service which maintains that mentally handicapped people are 'better off in the security and peace of the institution', and after all 'they like to be with their own kind'.

By definition, these people for whom there has been such rapid but piecemeal change in philosophy of care all have a $30 \%$ deficit or more of developmental and cognitive skills, but this does little justice to the heterogeneity of this group of people, most of whom have at least one or more other handicaps (Table 1).

TABLE 1. Disorders and handicaps found in association with mental handicap

\begin{tabular}{ll}
\hline \multicolumn{1}{c}{ Disorder } & \multicolumn{1}{c}{ Handicap } \\
\hline $\begin{array}{l}\text { Abnormality of muscle tone, } \\
\text { posture and movement } \\
\text { Blind or partial sight }\end{array}$ & $\begin{array}{l}\text { Locomotor/physical } \\
\text { Deaf or partial hearing, speech } \\
\text { or language disorder }\end{array}$ \\
$\begin{array}{l}\text { Epilepsy } \\
\begin{array}{l}\text { Psychiatric illness, } \\
\text { behaviour disorder }\end{array}\end{array}$ & $\begin{array}{l}\text { Communication } \\
\text { Physical deformity }\end{array}$ \\
\hline
\end{tabular}

The intellectual variation is wide within this group of people, from the totally unresponsive person who cannot score on any developmental test to the individual who can, in happier times, hold down a job in open employment and is capable of marrying, raising a family, taking on hire purchase agreements and going to vote.

When mental handicap is investigated, it is important to identify as accurately as possible the level of the skill deficits in all areas of learning and competence as affected by all the handicaps diagnosed, the social skills that could be developed for increasing independence and greater communication and those features that attract others to care for him. Perhaps most of all, those attributes must be found that enable him to be needed and, within his own ability, to make a contribution to his own family group. 
The second stage of diagnostic work is to widen the concept from the intrinsic skills and deficits that are in any case changing with maturation, to an existential understanding of the life of that handicapped person. His capacity to cope with his disabilities and use his skills in his immediate and more extended environment at this particular time of his life with his present care givers and current peer group will depend on his level of insight, personality, motivation and capacity to excite the caring instincts of others. The concept of handicap has then moved from a biological through a personal context to an interactional one, and the dynamic relationships of all family members where there is a mentally handicapped person becomes better understood.

As many as $80 \%$ of mentally handicapped children remain within their families, requiring both professional and voluntary support services. Fifty per cent or more of mentally handicapped adults remain out of long-stay hospital care, depending to a varying degree on alternative facilities to the home. Some will stay at home with ageing parents, some will be in private and voluntary care, in group homes, foster homes, vocational training residential units and a few in semi-independent living while others spend their time in a variety of residential settings, perhaps alternating from the parental home to an alternate home in a shared care arrangement.

A discussion of the effects of living with a mentally handicapped member of the family must be multidimensional; age is an important dimension, from the newly born child in whom the diagnosis of handicap has just been made and the knowledge imparted to the parents with a greater or lesser degree of skill, to the mentally handicapped middle-aged man at home with a widowed elderly mother whose own dependency needs overtake those of her son. The second dimension is the level and multiplicity of handicap, the third and fourth dimensions being the intrinsic skills for coping found within the family and the level of external support available.

\section{The coping skills of families}

Those who work within crisis-orientated services, where referrals come only after an unmet need has led to a deterioration of health, happiness or stability within the caring group, soon gain the impression that the handicapped child or adult inevitably strains the resources for coping to the point of breakdown. Such impressions of the damage that handicap can do within the family group lead to unnecessary gloom when imparting the diagnosis, underestimation of the level of expected functioning, prescriptive advice regarding the value of early residential care and rigid attitudes towards adoption for those couples who have a mentally handicapped child. Attitudes to the abortion of the imperfect fetus and infantile euthanasia for those who are deformed are also heavily influenced by the impressions gained from such crisis-orientated services.

However, from those who work within statutory services that aim at crisis prevention, or within voluntary organizations and also by the study of mental handicap registers, there emerges a different picture. This is one of many families who find within themselves remarkable strategies for coping, developing skills, responses and attitudes that may have otherwise remained latent had not one member of the family needed a more heavily dependent relationship than the rest. Many of these coping strategies when analysed are advantageous for all involved; some adversely affect certain members of the family but by minimal intervention at a counselling or psychotherapeutic level the strategy can be improved from potentially damaging to helpful.

Families with a mentally handicapped member may need help at four different levels. Firstly, there is a range of requests for practical and social support frequently met by local parent support groups, voluntary bodies and statutory agencies such as community nursing, health visiting and social work. Secondly, many families benefit from a close relationship with other parents to share the grief, the expectations and the joy over milestones achieved, through friendships where equality and a common purpose are the main strengths. Thirdly, the family will require, like any one else, professional help from the generic health and social services. A ready access to the paediatrician, the ophthalmologist, the accident and emergency departments, the family dentist, will ease the burden of having a different and 'special' member of the family within a family group who are finding comfort in trying to be ordinary. Sadly, access to such generic services is still often difficult and families repeatedly feel devalued along with their mentally handicapped member. Fourthly, families will need access to specialist services for education and for some health and social purposes, and these services must be available without the fight which many parents still recount with sadness and anger.

The mentally handicapped person needs access to similar levels of service. He will have a range of practical, social and educational needs to be met throughout his life and he will need, but rarely find, close friends; he will need to turn to peer groups, nonprofessional individuals and organizations as well as to professional help. However, as he becomes older his need to individuate becomes greater and his support systems should be seen as increasingly separate from his family. 


\section{Breaking the news}

The news of potential handicap may be broken during early pregnancy. The availability of antenatal diagnosis for screening for a few disorders, and, for many more disorders for mothers known to be at risk, raises not only the doubtful advantage of 'prevention' of mental handicap by destruction of the handicapped fetus but also the dilemmas that the professionals and every parent face concerning their acceptance or rejection of both amniocentesis and abortion and the meaning of handicap at a personal, family and societal level. The whole issue is clouded with value judgements based often on prejudice and inadequate knowledge, such that families may be subjected to ill-judged pressures concerning the acceptance of ante-natal diagnosis or, in the event of any abnormality being found, whether abortion should follow. Those parents who either refuse antenatal diagnosis or refuse abortion and subsequently give birth to a handicapped child carry a societally imposed burden of guilt known only to this and future generations.

The diagnosis of disease known to be associated with mental handicap may occur at birth when the typical physical abnormalities may be seen. Alternatively the suspicion of the presence of intellectual or other handicaps may increase during childhood as the toddler fails to reach expected milestones, and perhaps odd behaviours occur. For some children and families there is a devastating moment when sudden illness or an accident overtakes and the normal child is rendered abnormal as the result of acquired brain damage.

Whether the diagnosis is made at birth, slowly or suddenly in childhood, the reactions of the family are likely to follow the same broad pattern; that of mourning for the normal, perfect child who has not arrived or who has been transformed to abnormality, and the coming to terms with the real but imperfect child as he presents to them, both through direct contact with the child and through the information given to them by those who profess to know and care at the time.

A few well-chosen words, a solemn verdict

In those few seconds all hopes shattered

This small child so dependent

For ever.

Time will mean nothing to this child

He'll never know the hustle bustle

Of the daily round-the fuss

Never clutch the morning paper as he hurries

For the train or bus.

But motherlove is strong

You'll watch him grow while time stands still
To crawl, to walk, to run, to climb

To listen, speak, to write and read

A little. Yes, it has been known. (J.P.)

This dual reaction, the mourning for the loss of perfection and the acceptance of imperfection, can be seen as a major life event for both the family and the child, for the family for whom the total unexpectedness can be seen in terms of a 'novelty' crisis followed by a crisis in reality and reorientation; for the child for whom the label of 'handicapped, special or different' will have personal repercussions for his life style, his acceptance by his family and his understanding of himself in relation to others.

The mourning reaction is similar to that which occurs in bereavement: the initial stage of shock, panic and denial gives way to grief which may be projected on to others, professional care givers or members of the family, as anger and blame for what has happened. Introjection of grief leads to guilt about personal responsibility for the imperfection. A new form of stress, as the possibility of euthanasia is explored by professional and non-professionals alike, involves the struggle to identify personal and societal values concerning the role of the handicapped person in a complex industrial society where medical technology is available to prolong life and choices are being made about using such technology when handicap is present.

In most families with a congenitally handicapped child, the grief, anger and guilt give way, in part at least, to the strong desire to nurture that child however imperfect, and acceptance encompassing a strong sense of duty with the desire to nourish and protect leads to bonding between the mother in particular and the child, bonding which would normally have started earlier, unhampered by the various crises surrounding the birth of the handicapped child.

And though when you were born

It would not have seemed possible

I hardly think of you as different now At all

For you are you

No labels no categories

Just you

And I love you. (S.N.)

For the child in whom the diagnosis is reached by progressive failure to achieve milestones, the grief reaction may start when the doubts first enter the parents' mind, often before doctors are willing to share their doubts. Silence between doctor and parents at this time enhances the sense of isolation and creates a poor start for the psychological work 
that must follow in coming to terms with the diagnosis of handicap.

Those children damaged by accident or illness present a peculiarly difficult and tragic crisis for families to overcome. The clear memory of the perfect child with all his attributes and idealized future becomes caught in a moment of time and he remains the perfect child who would have reached all the goals in academic, sport, musical attainment or whatever was to be important for him. The 'death' of this perfect child may be enshrined in the family but at the same time he remains to be the model against which the achievements of the remaining siblings are measured.

The various reactions of the family members to the diagnosis of handicap will be affected by many factors. The advice that is available after diagnosis, where and how this is given and the sensitivity and knowledge within that dialogue, sets the scene for the acceptance of reality with sound knowledge of the biological facts and support systems, embedded in hope which will help counteract the wish to reject that which is imperfect. The expectations of the family for that child are important and will be affected by position in the sibship, sex of the child and social class of the family. Grandparental expectations may not have been in harmony with parental expectations in the first place, and brothers and sisters who had their own readjustments to make in any case to the new arrival in the family, may find unexpected levels of parental preoccupation, sadness, irritability and anger to which they have neither access nor explanation. Those siblings old enough to appreciate the family event may begin to muse upon the personal meaning for them at a time when few emotional resources are available to give them the support they need. The appearance of the child and his capacity to revive the maternal instinct even in times of deep grief will affect his future position in the family. The deformed child, in particular if the face is affected, the child surrounded by instruments in an incubator, the child who cannot suck, is having fits and may be near death, who screams continually, is hardly able to play his part in the bonding process. The immediate reaction of extended family, friends and neighbours may help or hurt. Many families will comment, possibly later, that it was after the birth of the handicapped child that very few birth congratulation cards were received.

\section{The pre-school years}

It is often imagined that the care of the young handicapped child differs little from the care of the normal baby and this is reflected in the pattern of national financial aid to families with a handicapped child. This is, however, far from the case. The care of the young mentally handicapped child differs both quantitatively and qualitatively from that of the normal baby. Frequently the child has difficulty over feeding, sleeping, and establishing routine, and may cry endlessly or be unresponsive. Those early mile stones of following a light, smiling, stilling when picked up that bring so much parental joy are frequently delayed. During toddler years excessive developmental delay in locomotor skills, communicating and relating may reveal other handicaps that frequently are associated with intellectual handicap. The autistic child who usually has a degree of mental handicap may present in these years with apathy, withdrawal, visual avoidance, repetitive movements and unexplained misery that are seen in retrospect to be classical early symptoms of infantile psychosis. Too often is mother's intuition blamed on her tendency to fuss and too rarely is an apology given when she was right after all.

Not only is the child both quantitatively and qualitatively different to care for, but the parents are still needing time, personal space and support to come to terms wth their unexpectedly handicapped child. The uncertanties of the extent of handicap at this early stage may allow some denial to continue and for father, who rarely is involved with the care of the young child, absence of daily contact does not help him through denial to acceptance. Neighbours may not know how to respond and prefer to ignore, the local baby-sitting circle are not certain about inclusion of the child and hope that the mother will not ask to join, the friendly health visitor may be replaced by a special home visitor from the service for handicapped children and the general practitioner may be honest enough to confess that he has never heard of the particular syndrome if the condition is rare. Mother dreads that first trip out to the shops with the pram when those who remembered her pregnant will expect to gaze with admiration on the perfection of the new arrival.

Parents with personal resources who have worked through the initial shock and grief frequently turn to non-professional support groups for help, information and time to talk and learn. Rarely are they disappointed. Others relate to a professional person, trusting him to see them through those difficult early years when uncertainty and alienation may threaten to split the family from within, between the generations, and the family from the neighbourhood.

Support systems, be they professional or voluntary, must meet the needs of families both at a practical and a counselling level. The nurse who visits mother with a supply of incontinence pads and has time to enjoy the baby talk no longer to be shared with neighbours, the psychologist who visits to encourage daily living skills development and shares the joy of achievements gained, as well as the pain, both help to 
balance the heedless comments made by those onlookers who decide it would be better 'if he were put away'.

On the road to the beach he lost his shoe, Stopped running, went back,

And feebly dangled his foot over the missing shoe-

A timid venture into responsibility. (J.H.)

In later toddlerhood care begins to move from the home to the play-group, to the homes of friends and neighbours when more questions are asked, judgements made, blame apportioned and the negative views of effects on the family are gratuitously offered. When play-group facilities are associated with health service facilities then the image of the sick child is reinforced. Better that they are associated with educational and voluntary provision, and wherever possible mixing the handicapped and the normal child to provide models for development and to prevent the segregation of the handicapped child so easily perpetuated throughout his life.

Many parents will realize and respond to the greater time required to provide the mothering needed and will be sensitive to the repercussions on the other children. Most vulnerable will be the sibling born before the handicapped child whose own dependency needs may be only partially met unless the entire family have the capacity to adjust and share the work-load.

When she was at home the rest of us got shoved out a bit but we didn't mind because living with her for so many years made us realise we would not get as much attention as Linda got. (M.T. aged 14).

For younger parents, the need to consider the risks for a further pregnancy will be paramount and the picture in the past of the handicapped child being the last in the family reflected not only the parental response to handicap but the inadequacy of genetic knowledge. Now parents can expect a risk factor and if ante-natal diagnosis is relevant, they may embark on another pregnancy with reasonable confidence for a normal child who will then be younger than the handicapped child and may be competing for parental time. Later he will overtake the handicapped child, and will need to come to terms with having an older, less able brother or sister to help, protect and support.

Within a service for handicapped people and their families there will always be well known examples where a combination of handicaps presents within the sibling group.

\section{Case reports}

(1) Out of the first five pregnancies, Mrs S. had three miscarriages, one still-birth and one anencephalic child. The sixth pregnancy resulted in a daughter with Down's syndrome. Devotedly cared for, she was a delightful and rewarding member of the family. Unwilling to embark on a seventh pregnancy the parents requested adoption but had grave difficulty in finding a society who would accept them as resilient enough to provide a 'normal' home for an adopted baby.

(2) The first child was born with severe spina bifida. He did well intellectually despite appalling physical handicaps. Because of the genetic risk the parents decided to adopt their second child and the 'perfect' daughter was placed with them. She developed profound mental handicap and uncontrolled epilepsy of unknown cause.

Families such as these who find within themselves great resources for coping with their own unanswered questions about such repetitive tragedy, demand from the services great respect in recognition of their resilience to cope with unbelievable disappointment.

\section{The school years}

School years for a mentally handicapped child frequently begin at two and a half years and last until 19 years, usually in a special school known to be for mentally handicapped children. The child who attends a special school is immediately different from his potential peer group and travelling by coach, usually further than his siblings, he does not find his local play mates through contacts at school. He is known as different and a target for derision, for rejection and therefore loneliness despite his education being entirely appropriate and of a high standard. The choice of a special school may be dreaded by the parents who were clinging to fragments of denial by hoping that the local school would cope. While many parents find the environment of the special school supportive both to their child and themselves and become involved in activities there, others continue to grieve the choice and transfer some of the anger and guilt concerning handicap to the school staff who then become 'responsible' for the failure to progress.

Evening activities are difficult to find. Uniformed organizations often do not take mentally handicapped children, sporting clubs may have too high a standard and the local group of children may reject the mentally handicapped child who finds his own friends through playing with children much younger than himself. Rejection and teasing in the local community may lead to misery, and parental protective anger to a neighbourhood quarrel. The television 
becomes the inevitable filler of time and isolation increases.

Johnny is twelve, but he seems nearer three.

His babyish bouncing is scaring for me,

Little boys run, when he wants them to stay,

Because of his size, and the way that he'll play.

So Johnny is left alone most of the day,

It's no wonder he's lonely when things go this way.

(A.J.S. aged 10)

Siblings of normal intelligence are experimenting with increasing independence, friendships, skill building and hobbies development; competition pervades their lives, acquisition of belongings is important and they are beginning to learn about the wider world beyond home, family and school, making judgements on abstract matters and developing a capacity to be discerning. Their lives are rich and relationships with parents increasingly equal with shared interests. By contrast the mentally handicapped child learns slowly, all achievements are painstakingly acquired with help from the family, independence may never come and behaviour of earlier developmental stages may linger. Life seems uneventful and may be seen to be spoiling or holding back other activities in the family or the development of mutual interests. The wet theatre seat, the unmanaged sneeze, the giggle in the sermon, no invitations to birthday parties, are all reminders that there is a long way to go.

\section{Case report}

Claire had Down's syndrome. Her family were all keen on sailing and her two brothers began to enter national competitions. Claire was terrified of water and could not swim. She became the recipient of so much family resentment that finally a boarding school place was needed with residential care in the holidays.

Behavioural disorders may accentuate any stress in the family which then may perpetuate or make worse the behavioural problem. Problems such as running away may lead to locks and barriers preventing free access or exit to anyone, destructive behaviour means that precious belongings must be guarded or locked away, noisiness upsets neighbours and disrupts homework and hobbies, sleep disturbance has repercussions on everyone and the frequent solution of allowing the child in the parental bed has inevitable effects on the marriage; aggresion towards siblings, parents or pets can be devastating and brothers and sisters will in general find it hard to comprehend the different disciplinary methods and standards of behaviour acceptable to parents for themselves and for their handicapped sibling.
Ted had begun to bang the door,

And stamp his feet upon the floor

He meant no harm; he knows no better.

He's hidden that important letter,

That came this morning through the post.

If he bangs the wall again,

The next door neighbour will complain.

They've had enough of that they said.

They don't like poor afflicted Ted. (M.S.)

The 'parental child' is a well-known finding in some families where one older sibling has responded or has been encouraged to fulfil the role of an additional parent, providing much needed caregiving time, but at the cost of premature maturation for himself and a distortion of the normal transgeneration boundaries.

Few families now choose residential care during school years and if this happens the reasons are usually due to parental ill health, marital breakdown, unusually severe dependency needs or behavioural problems. Happy the family when a boarding school place is found for the child where the educational ethos remains appropriate. However there are inadequate numbers of boarding schools for severely mentally handicapped children and most have to use health or social service accommodation when the usual pattern is for repetitive short stay admissions rather than long stay care, thus easing the total burden of care but creating repeated separation experiences for children to cope with at a developmental stage when the time concept is often poorly developed.

He grows and goes to the subnormal school, And learns to count to four and spit and kick, To paint and draw, to dance, chatter and curse. Tranquility and quietude have flown:

Commotion, crying, cuddle, quarrel, kiss:

He needs the discipline of boarding school.

Yet can they part? (D.W.)

Whilst much help from parents with a school-aged mentally handicapped child comes through the educational system there are many other channels of help to minimize the difficulties. A social support network for the child, a sitting-in service and volunteers who act as befrienders for siblings under stress will all help the family to cope. In some parts of the country, siblings of handicapped children meet in groups for mutual support and newsletters encourage communication for self help.

\section{School leaving and adolescence}

The transition from school to adult life is perhaps 
the most difficult time for both the mentally handicapped person and the family. The support systems that were evident soon after the diagnosis, that surrounded the pre-school and even more the school years fall away as adulthood looms with all the uncertainties of the future, the threats of inadequate residential care, the increasing age of the parents and the departure of helpful and supportive siblings.

Before adolescence there is the charm of childhood that makes acceptance easier for the family and others; whether physically handicapped or overactive, small physical stature means that physical care and control is easier whether the child is in the bath, in the supermarket or at a party. Cuddles are as appropriate as are ribbons in the hair and ankle socks. Adolescence brings a sudden increase in physical stature but not inevitably in cognitive development, child-like clothes are inappropriate and means of control such as holding hands no longer seem right. The onset of menstruation and masturbation means that sex education is necessary or the family and society will be offended and the mentally handicapped person risks rejection as never before. A sense of propriety must be acquired, but how? Is he really capable of shutting and bolting the lavatory door?

Many parents dread the adolescent phase when equally adolescent siblings begin to evaluate their handicapped sibling's role in the family. Perhaps for the first time they criticize parents for their untiring efforts through the years as the adolescents seek and find new solutions to unsolved problems while working through their own identity crisis. For the first time they become embarrassed about bringing their friends to the home and begin to think of their own sexuality, capacity to have normal children and acceptability to the other sex in the presence of a handicapped sibling. The mentally handicapped adolescent needs a youth club, heterosexual contacts, recreational skills as well as outlets, he needs privacy, a chance to begin to take risks, to make choices and mistakes. All this within the cognitive framework of the 5-6-year-old? The dilemma for parents is great, especially as the sexuality of their mentally handicapped child reminds them of their own sexuality that brought him into existence.

Adolescence in the mentally handicapped person is a time of biological, social and emotional change but the starting points may be so different from the normal brother or sister. Biological changes may include the onset of epilepsy, and an emotional change may be the development of depression so frequently seen, for example, in autistic adolescents. The social changes are often a contrived tangle of supposedly increasing freedom with greater peer group contact but often with parents of necessity staying close behind.
The letting go of the adolescent of normal intelligence from the home is associated with independence skills, work opportunities and possibly marriage allowing a promotional atmosphere to pervade the departure, however much the preceding months have been marred by dissent and conflict. The mentally handicapped adolescent may sense that such a promotional move is not for him and neither is marriage. When community care is misinterpreted as care in the home with minimal support service, until the parents can cope no longer through age or illness, then this artifically extended home care is frequently a trap into which the mentally handicapped member unwittingly falls with no prospect of moving, marrying or making money. Small wonder that this is a time of increased mental illness in mentally handicapped people as well as increased parental stress and ill health. If the departure of the other adolescents in the home has been accompanied by unresolved relationship difficulties then the 'permanence' of the mentally handicapped member in the home may be realized initially with gratitude and the possible loneliness of the marital couple is obviated by his continued presence. 'At least he will never leave us. $\mathrm{He}$ is our permanent baby', is an attitude which denies his approaching adulthood and his right to an individuation process tailored to his own skills and needs.

Daily occupation for mentally handicapped adolescents, once they have left school, is almost entirely within social educational centres with little opportunity for open employment unless the sympathetic small family business can take on the handicapped member. Unfortunately, with increasing unemployment in teenagers of dull normal intelligence, the increasing life span of mentally handicapped people and the rapid increase in numbers remaining outside the institutions, social education centres are frequently full and the severely handicapped school leaver may be returned to his home with no prospect of day care other than the occasional attendance at the local mental handicap hospital, unacceptable to many parents. This is a crushing blow to the individuation process started within many a progressive special school and is rightly entirely unacceptable to the family.

Fortunately some mental handicap services have anticipated the many changes and potential crises that are part of the life of the mentally handicapped adolescent. School leaving may now be followed by a period of tertiary education at the local further education college or by vocational training schemes, some of which are residential and are seen as equivalent to the University or College placement for the other siblings. An alternative home locally in a hostel or group home, and for the more handicapped in health service accommodation (small domestic 
units), provide the promotional atmosphere for a change of residence at this time.

Peer group experiences sufficiently supervised to cope with parental anxieties, adequate and realistic sex and interpersonal relationship education, advice on appropriate dress and general appearance, all enable the mentally handicapped adolescent to experience the transition from childhood to adulthood in a way that further enhances his social and cognitive maturation and helps the parents in the process of letting him go. Parents may need to be helped to be less involved in decision making and to allow others a greater part of the caring role.

Within these better services of crisis prevention at adolescence, the question of sterilization of the mentally handicapped girl or boy now rarely arises and the anxieties are usually resolved by explanation, education, contraception and adequate supervision. While mentally handicapped young people may develop heterosexual friendships, most of these remain at a platonic or semi-platonic level and only a few seem to want, or are capable of, a full physical relationship. It is important that their sexual needs and drives are fulfilled in ways that are appropriate and acceptable to the person and to the family. A few, however, suffer intense frustration which may lead to sexually deviant behaviour. Many are aware of their normal siblings' capacity for marriage and parenthood. The deflection of attention and devotion to the perfect grandchild may cause a strong reaction to the point of depression, or aggression towards those who have newly entered the family circle and are competing by displaying similar dependency needs to the mentally handicapped member. A full and varied life of his own with a chance to establish personal identity, experience achievement in any sphere and the chance to move away from the family group like brothers and sisters will all help to avoid the image of a tangle of incompetence where adolescent difficulties bring only a new wave of despair to the family group.

\section{Adulthood and death}

By adulthood, the mentally handicapped person should have experienced adequate education, social stimulation should have developed to a maximum their potential skills and specialized help should have minimized their deficits and secondary handicaps. Childhood has been put away, adolescence has been a challenge but not a burden and a secure, alternate home has been provided with parental contact and dialogue no longer overshadowed by an unrelinquished burden of care for the parents. Sadly for many mentally handicapped adults the perfect service has been unavailable and they have been placed in inappropriate environments such as the large ward of the mental handicap hospital, deprived of their possessions, privacy, friends and familiar surroundings. Depression and behaviour disturbance frequently follow. Those who remain unsupported other than by ageing parents frequently experience a diminution in the quality of their social life which follows the common pattern of parental withdrawal from social contact with their increasing age. While much can be done with voluntary services and an extension of the social education centre's activities into a recreational role, for most if not all, the best alternative is a substitute home where age-appropriate activities may be maintained.

\section{Case report}

John is 50 years old with severe mental handicap, cerebral palsy and epilepsy. He lives with his mother aged 80 who has severe hypertension. John's epilepsy became out of control and his mother suffered a stroke through uncontrolled high blood pressure. A home visit revealed 50 pill bottles on the kitchen window sill. John cannot read and mother's undiagnosed cataracts had caused her to make many mistakes in finding the correct medication for herself and for John. The admission of John and his mother to warden-controlled accommodation gave them both further years of happiness in each other's company with adequate supervision until the death of the mother. Sadly for John, there was no alternative to the mental handicap hospital.

The death of a care-giving parent may bring a double loss; the loss of a loved one and the loss of a home. The meaning of such losses are frequently underestimated on the assumption that the mentally handicapped person does not understand death. However, he understands loss and the lack of a time concept is of no help to him to cope with his grief. The mentally handicapped person should be allowed to join in the collective bereavement rituals surrounding the death, he should be taken to the funeral even though he may not behave appropriately. An advocate or volunteer could take the burden of care for this sad occasion allowing the family to be complete. If he is excluded from the grieving rituals then his unexpressed sadness may be translated into a psychiatric illness which is either unrecognized or not related to his loss. Many efforts are now being made to help mentally handicapped people of all levels of cognitive ability to come to terms with significant loss, the approach being similar to that of the work with children who suffer separation from their parents.

Many parents, left to support their mentally handicapped dependent to adulthood, having rejected the services or finding none to turn to, become preoccupied with the ongoing care when they will be 
unable to provide a home. Sons and daughters may be called upon and expected to help but rarely is this successful nor is it often appropriate. Parental anxiety may be so severe that euthanasia is seen to be the only way to ensure that the mentally handicapped dependent does not linger unloved and unknown in the dreaded (but probably untested) institution. This anxiety has caught the imagination of some voluntary organisations which now organize volunteer visitors and housing schemes for which a financial contribution in the form of an insurance can bring peace of mind.

However, death may come first to the mentally handicapped member of any age and parents who have made a whole-hearted commitment to care, having grieved the loss of non-arrival of the perfect child, now find the grief over loss of the imperfect child whom they have come to love, peculiarly and poignantly painful. This grief is associated with the loss of the life that never reached expectations, the life that called forth a reappraisal of values within the family, that altered family dynamics for good or bad, the life that commanded caring skills above all and gave back in return something that was unique and cohesive through the quality of imperfection. Families that lose a handicapped member need support so that another major readjustment can be made to the loss, as it was made to the arrival of that handicapped person. Bereavement counselling should be available when requested to help the family once more adjust to loss and once more find direction and a sense of purpose.

\section{Conclusion}

The family with a mentally handicapped member has to make major adjustments to include that person whose dependency needs call for variations in established family relationships and may unknowingly redirect the entire family in terms of goals, values and attitudes. The majority of families cope so that all or most of the family members gain from this experience and these intrafamilial resources for coping are frequently underestimated by those who attempt to help.
Assistance may be required at a personal level, at the level of the family and in relation to the family, the neighbourhood and society in general. Adverse reactions and unresolved difficulties within and outside the family relate as much to philosophical issues of the value of the handicapped person in society as they do to unmet practical and social needs.

Help that is most relevant to the family is help that emphasizes normality rather than abnormality and assists the family to increase their own resources for coping rather than increasing their dependency on others. Voluntary bodies, the personal social services and health authorities must together develop networks of care and support which families can use to the mutual benefit of all members.

These people are called mongols

They're every shape and size

But we of course ignore them

Because we're civilised. (P.D.)

\section{Bibliography}

Poems quoted in the text are from Answer me World, an anthology by and about the Mentally Handicapped, edited by Christine Zwart and Peter Pascoe, NSMHC, now the Royal Society for Mentally Handicapped Children and Adults, 123 Golden Lane, London ECIY ORT.

Suggested further reading:

CoOK, D. (1978) Walter. The Alison Press/Martin Secker \& Warburg, London.

Hannam, C. (1975) Parents and Mentally Handicapped Children. Penguin Books, Middlesex.

Hanvey, C. (1981) Social Work with Mentally Handicapped People. Heinemann Educational Books, London.

Kew, S. (1975) Handicap and Family Crisis. Pitman, London.

LANSDOWN, R. (1980) More than Sympathy. Tavistock Publications in association with Methuen, London.

MCCORMACK, M. (1978) A Mentally Handicapped Child in the Family-A Guide for Parents. Constable, London.

Sarnoff, Schiff, H. (1977) The Bereaved Parent. Crown Publishers, New York.

SHEARER, A. (1981) Disability: Whose Handicap? Basil Blackwell, Oxford.

Whelan, E. \& Speake, B. (1979) Learning to Cope. Souvenir Press, London. 